\title{
Role of Endourological Procedures (PCNL and URS) on Renal Function: a Systematic Review
}

\author{
Thomas Reeves $^{1} \cdot$ Amelia Pietropaolo $^{1} \cdot$ Nariman Gadzhiev $^{2} \cdot$ Christian Seitz $^{3} \cdot$ Bhaskar K. Somani $^{1}$
}

Published online: 21 April 2020

(C) The Author(s) 2020

\begin{abstract}
Purpose of Review To present the latest evidence related to the impact of ureteroscopy (URS) and percutaneous nephrolithotomy (PCNL) on the renal function.

Recent Findings Our review suggests that the overall renal function is not detrimentally affected by endourological interventions (URS, PCNL). This is however influenced by the preoperative renal function, presence of comorbidities such as diabetes and hypertension. For PCNL procedures, tract multiplicity, preoperative UTI, and postoperative bleeding also contribute to a decline in renal function.

Summary This review suggests that endourological interventions do not adversely affect renal function and tend to improve it in patients who do not have a poor renal function prior to the procedure. Several factors including poor preoperative renal function, diabetes, hypertension, and multiple percutaneous tracts appear to predispose patients to declining renal function after procedure, and these patients should be counseled for and followed up appropriately.
\end{abstract}

Keywords Renal function $\cdot$ eGFR $\cdot$ Ureteroscopy $\cdot$ PCNL $\cdot$ Creatinine $\cdot$ Chronic kidney disease

\section{Introduction}

Kidney stone disease (KSD) is rising with a lifetime prevalence of $14 \%$ [1-3]. Surgical options such as shockwave

This article is part of the Topical Collection on Endourology

Bhaskar K. Somani

bhaskarsomani@yahoo.com

Thomas Reeves

reevesth@gmail.com

Amelia Pietropaolo

ameliapietr@gmail.com

Nariman Gadzhiev

nariman.gadjiev@gmail.com

Christian Seitz

drseitz@gmx.at

1 Department of Urology, University Hospital Southampton NHS Foundation Trust, Tremona Road, Southampton SO16 6YD, UK

2 Department of Urology, Pavlov First Saint Petersburg State Medical University, Lva Tolstogo 17, Saint-Petersburg, Russian Federation 197342

3 Department of Urology, Comprehensive Cancer Centre, Medical University of Vienna, Vienna, Austria lithotripsy (SWL), percutaneous nephrolithotomy (PCNL), and ureteroscopy (URS) are all used as treatment modalities [4-6]. The chosen treatment often depends on stone characteristics, patient fitness, comorbidities, surgical expertise, and underlying renal function. Preoperative assessment of these patients involves up-to-date imaging, urine culture, renal function, and fitness for a general anesthetic. The overall incidence of KSD has been rising, and hence more patients are subjected to surgical intervention $[7,8]$.

Kidney function can be impaired as a result of the disease, urinary infections, or ureteric obstruction related to the stone or surgical intervention related to the KSD. While it is generally believed that treatment of KSD would lead to an improvement of renal function, it is unclear if the surgical procedure required to remove the stone will have an adverse effect. There is a theoretical risk of deterioration of renal function with both PCNL and URS. The physical puncturing of the kidney during PCNL causes direct damage to the renal parenchyma, and this is amplified as PCNL is increasingly used to treat complex or staghorn calculi requiring multiple puncture tracts [9]. During endoscopic approach to the urinary tract, high pressure irrigation is often required to maintain a visual field, causing dilatation of the renal calyces that could potentially harm the function of the kidney. In addition, while the renal 
parenchyma is not breached as with PCNL, application of the holmium:yttrium-aluminum-garnet (Ho:YAG) laser may cause heat related tissue damage $[10,11]$.

Given the theoretical risk of renal function decline with both PCNL and URS, our aim was to conduct systematic review to clarify the effect of endourological interventions on renal function.

\section{Method}

\section{Search Strategy}

Our systematic review was performed as per the Cochrane guidelines and Preferred Reporting Items for Systematic Reviews and Meta-analyses (PRISMA) checklist [12]. The databases searched included MEDLINE, Cumulative Index to Nursing and Allied Health Literature (CINAHL), Excerpta Medica Database (EMBASE), Scopus, Clinicaltrials.gov, Google Scholar, Cochrane library and Web of Science with references cross-checked, and individual urology journals also hand-searched. The search terms included "stones," "calculi," "urolithiasis," "nephrolithiasis," "kidney," "renal," "ureteroscopy," "URS," "laser," "fragmentation," "percutaneous," "PCNL," "mini," "miniaturized," "percutaneous nephrolithotomy," "lithotripsy," "renal function," "kidney function," "chronic kidney disease," “CKD," “creatinine," "eGFR," "MAG3,"and "DMSA." The references of identified studies were examined to find any further potential studies for inclusion. Boolean operators (AND, OR) were employed. The research was limited to English language articles from 1990 to June 2019.

A cut off of ten patients was set to include studies from centers with minimum relevant endourological experience in managing stones. All original studies were included, and where more than one article was available, the study with the longest follow-up was included. Experienced reviewers (TR, AP) not involved in the original work independently identified all the studies that appeared to fit the inclusion criteria, which were then included for a full review. All discrepancies were resolved with mutual agreement and consensus with the senior author (BKS).

\section{Inclusion Criteria}

1. Studies reporting on renal function of patients following endourological intervention (PCNL and URS)

2. Studies reporting on a minimum of 10 patients

3. Studies available in English

\section{Exclusion Criteria}

1. Laboratory, animal data, or review articles

2. Studies published before 2000

\section{Data Extraction and Analysis}

The following variables were extracted from included studies: author, year of publications, journal, country of study, treatment modality, patient characteristics, stone characteristics, method of monitoring renal function, follow up, and preand postoperative renal function. Data were collected using Microsoft Excel 2019 (version 16.28). Due to the heterogeneity of the included studies, the authors decided that metaanalysis of effect sizes was not suitable, and hence either pooled analysis was performed to calculate mean values or outcomes were summarized in a narrative fashion.

\section{Quality of Studies Assessment}

The Centre for Evidence-Based Medicine criteria were used to evaluate the levels of evidence of the included studies [13]. The quality of reporting outcomes was performed according to the Strengthening the Reporting of Observational Studies in Epidemiology (STROBE) statement [14].

\section{Results}

\section{Study Selection and Characteristics}

The literature search yielded 837 publications (Fig. 1). After excluding reports that were out of the scope of our systematic review, 145 abstracts were reviewed of which 39 full articles were reviewed for inclusion. Twenty-eight studies were included in the final review ( 5 were excluded as they were published before 1990, 4 did not mention the effect on renal function, 1 was an animal study and 1 was not in English language). Included studies were published between 2001 and 2019. Three papers compared the effect of PCNL and URS on renal function (Fig. 1).

\section{PCNL}

The effect of PCNL on renal function was assessed in 21 studies published between 1999 and 2019. This included 1994 patients, and the mean age of patients was 49.3 years (Tables 1 and 2). The follow-up in these studies ranged from 1 day to 51 months $[15,16]$. While 11 studies [15-26] used blood test to measure renal function, 1 study [27] used radionucleotide scans and 8 studies used combination of both [28-35]. 
Fig. 1 PRISMA flow chart of the included studies

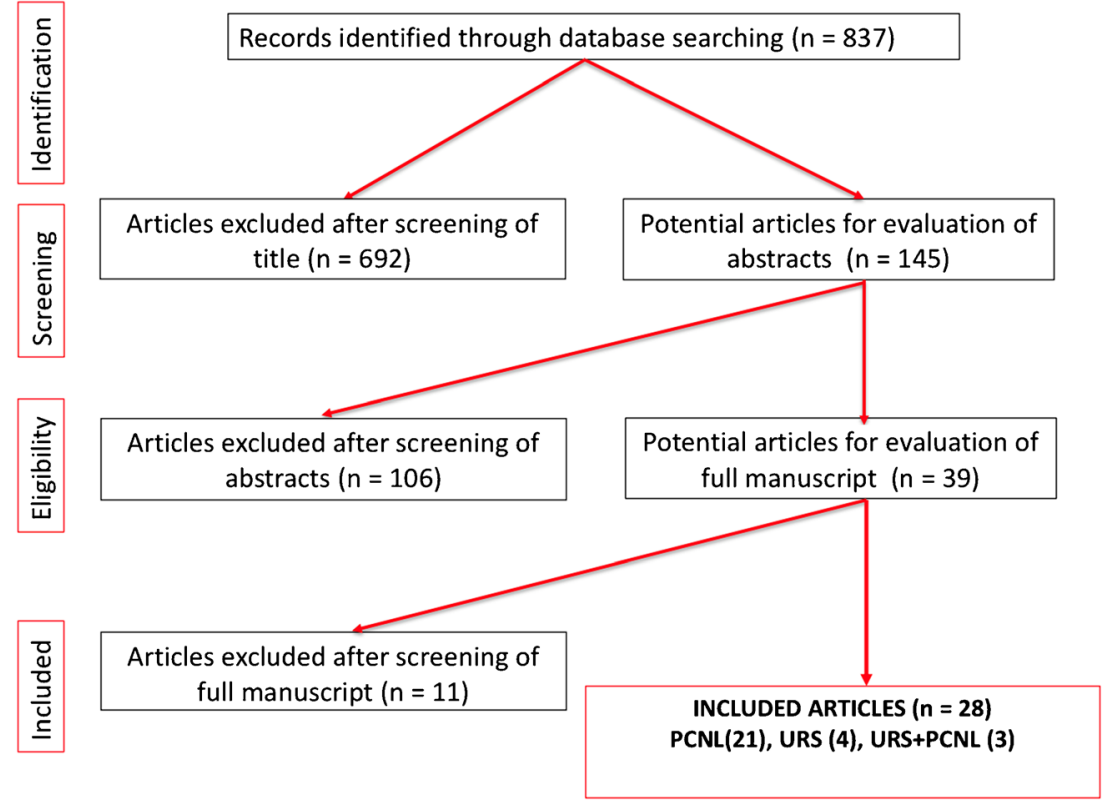

Three studies showed significantly improved renal function following PCNL [19, 30, 35]. Eight studies showed no significant improvement but a trend toward improved renal function [16, 17, 23-25, 28, 29, 34]. Eight studies showed no significant change in renal function [18, 21-23, 26, 27, $32,34]$. Handa et al. showed that on day 1 post-procedure the renal function was significantly worse [15].

Hegarty et al. showed significantly worse renal function in patients who underwent multiple tracts PCNLs, but no significant change in those with single tract approach [20]. Fayad et al. showed that those with poor preoperative renal function had significantly worsened renal function post-procedure, but those with normal preoperative function had a stable renal function [31]. Fayad, Ozden, and Chi et al. showed that diabetes was associated with poor postoperative renal function $[17,23,31]$. In addition, Fayad et al. and Ozden et al. showed that postoperative UTI was associated with poor postoperative renal function $[17,31]$. Perez-Fentes et al. suggested that postoperative complications were associated with more parenchymal damage following PCNL [33].

\section{Ureteroscopy}

The effect of ureteroscopy on renal function was assessed in four studies published between 2014 and 2019 [36-39] (Tables 1 and 2). This included 608 patients, 355 males and 253 females, and the mean age of patients was 54.9 years (Table 1). The follow-up ranged from 4 weeks to 28.1 months $[36,40]$. All 4 studies used blood tests (creatinine, eGFR) for renal function monitoring [36-39].

Yang et al. [36] showed that URS significantly improve postoperative renal function. The other three studies showed no statistically significant change but trend to improvement in postoperative renal function [37-39].

\section{Comparative Studies between PCNL and URS}

Three studies included both PCNL and URS published between 2016 and 2019 (Tables 1 and 2). This included 262 patients with a mean age of 57.3 (Table 1) [40-42]. The follow-up ranged from 60 days to 90 days. Jiao et al. and Cho et al. used blood tests (creatinine, eGFR) to measure renal function while Piao et al. used combination of blood test and radionucleotide scans [40-42].

Both Piao et al. and Jiao et al. showed no significant change in renal function but a trend towards improvement [40, 42]. Cho et al. showed that if preoperative renal function was normal and then postoperative renal function was statistically normal, but if the renal function was abnormal, then it had a tendency to deteriorate significantly postoperatively [41].

\section{Quality Assessment}

The Centre for Evidence-Based Medicine criteria were used to evaluate the levels of evidence of the included studies and found that 3 studies were level one [18, 28, 30], 11 were level two [16, 21, 26, 27, 29, 31-33, 38, 41, $42]$, and 14 were level three evidence ( $[15,17,19,20$, 22-25, 34-37, 39, 40])(Table 1). In addition, the quality of all studies was assessed for inclusion against the STROBE criteria [14]. 


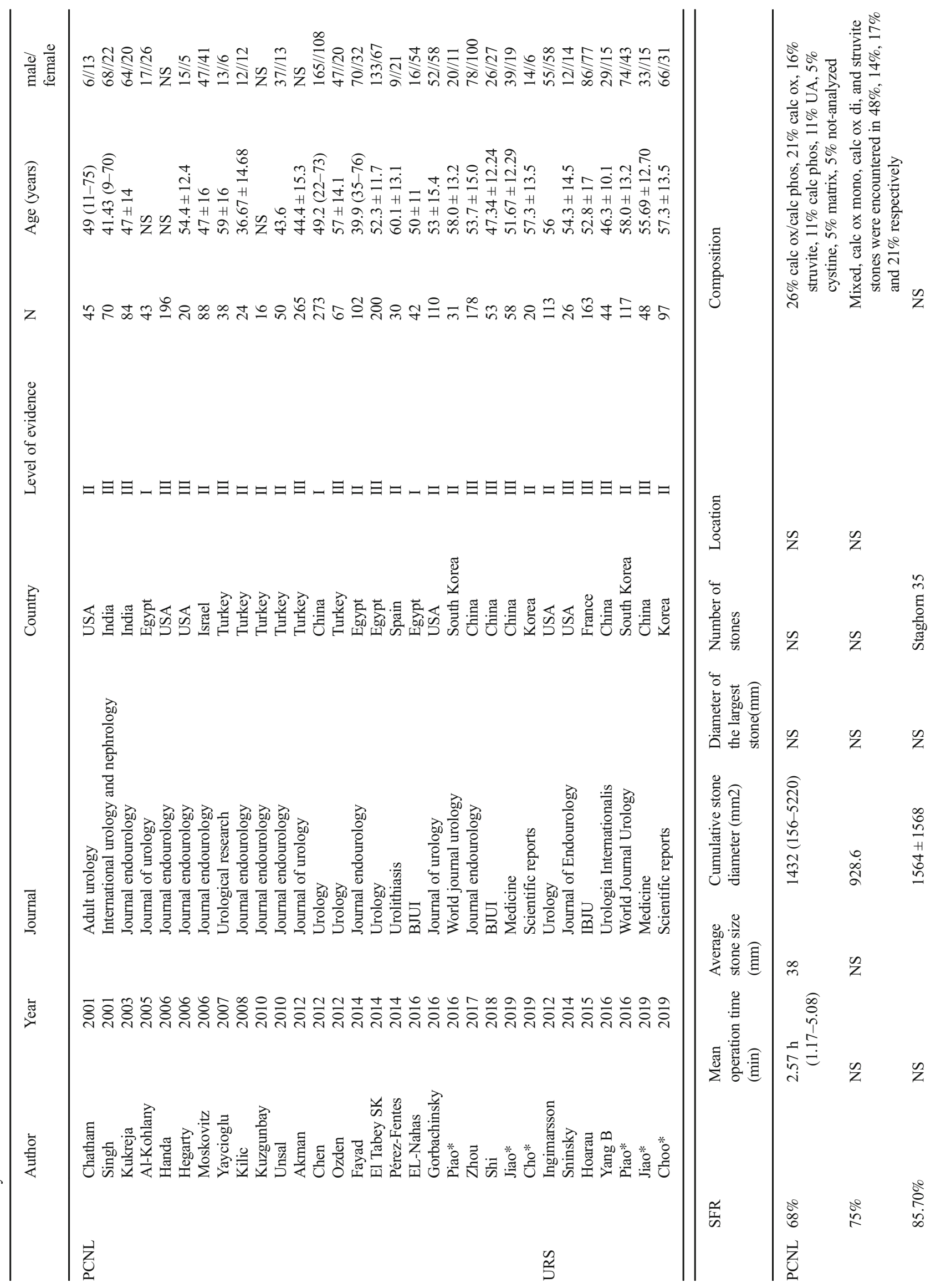



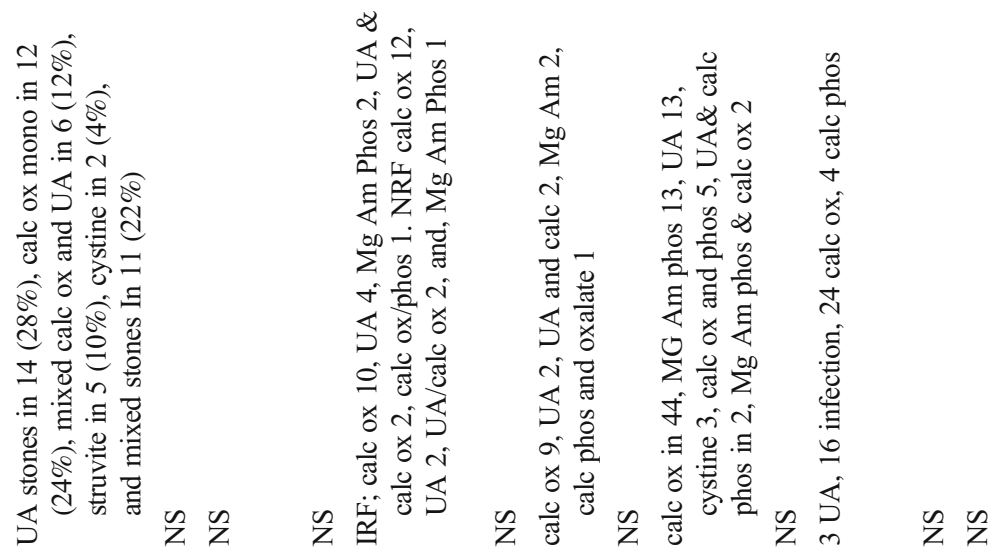

象照

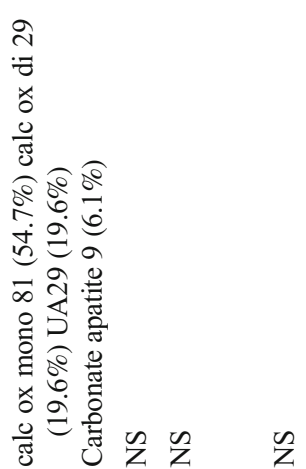

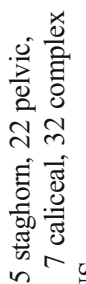

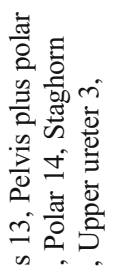

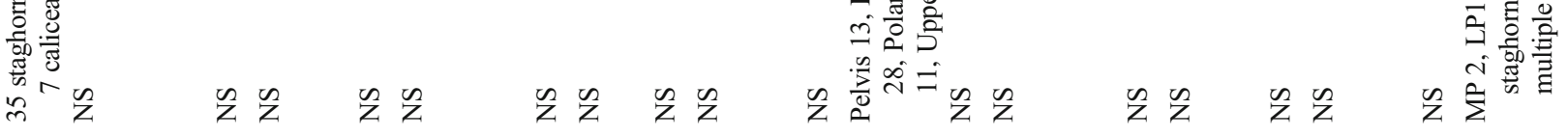

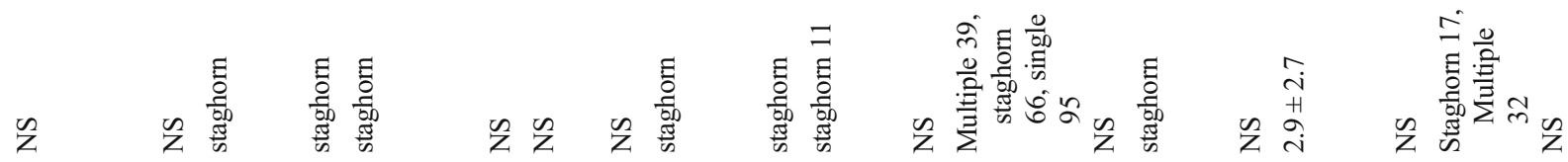

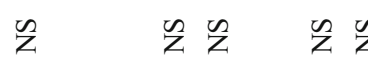

足 Z

$\sum \tilde{z} \quad \tilde{z} \tilde{z}$

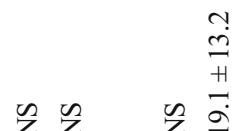

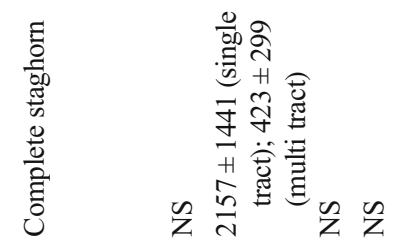

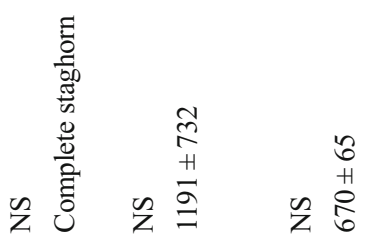

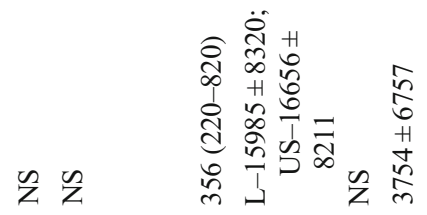

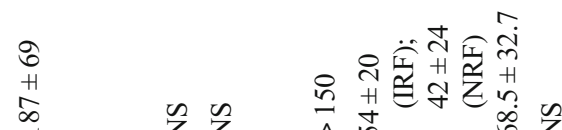

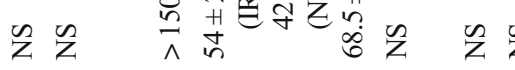

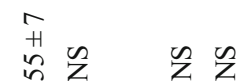

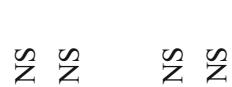

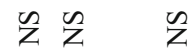

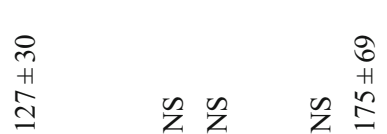

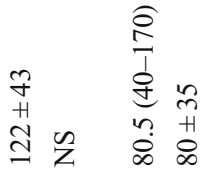

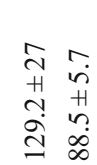

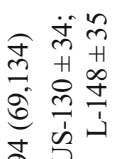

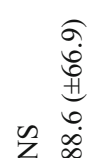

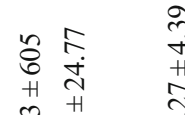<smiles>C1CCCCC1</smiles>

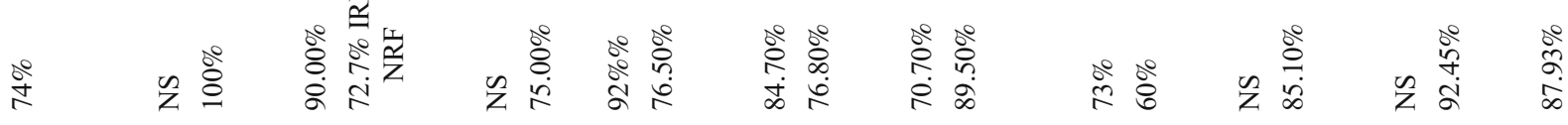



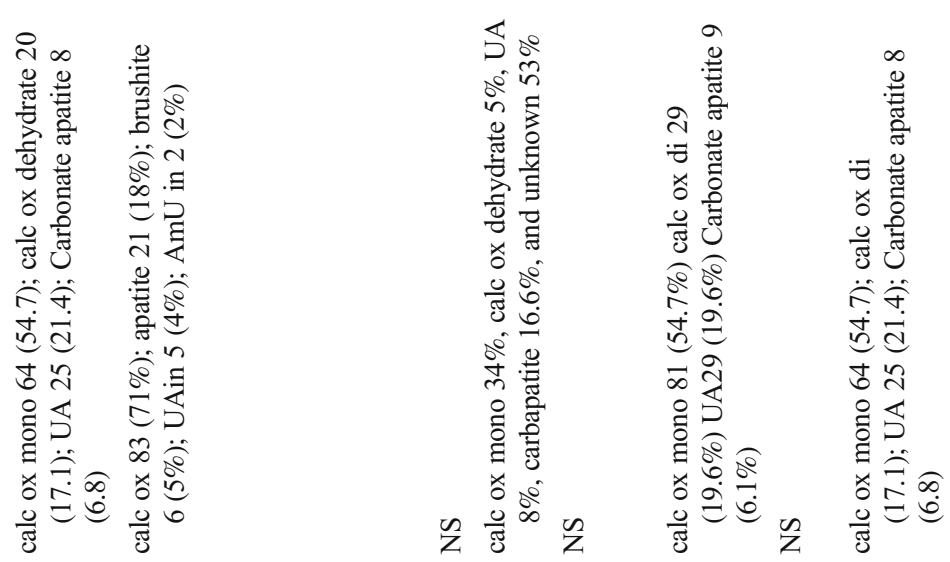

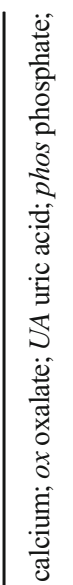

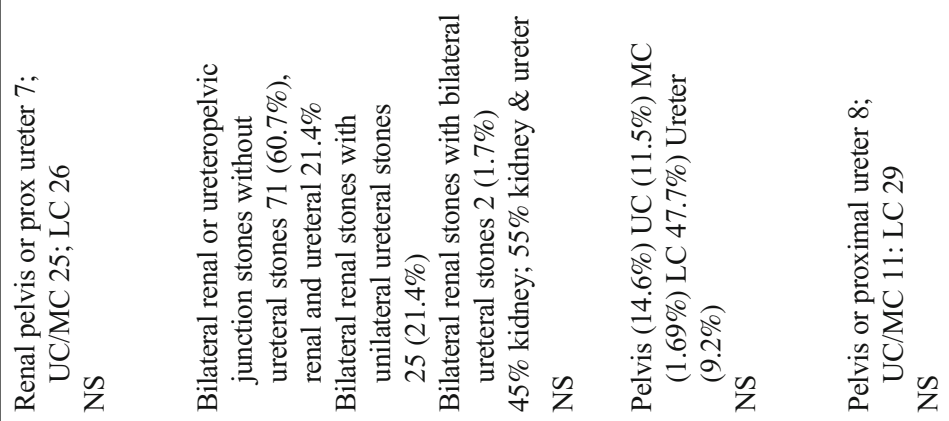

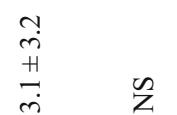

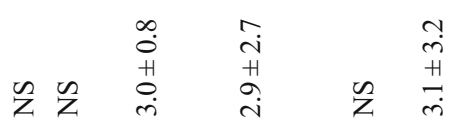

$\begin{array}{ll}\stackrel{0}{n} & \\ \stackrel{n}{H} & \\ \stackrel{n}{I} & n\end{array}$

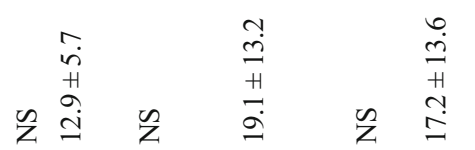

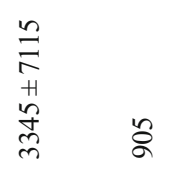

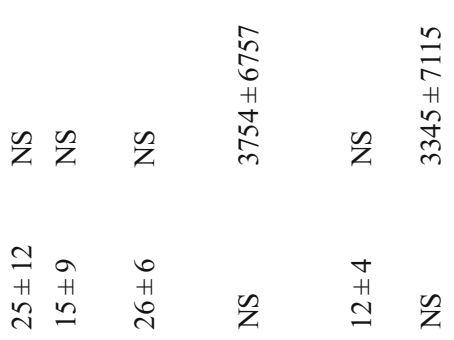

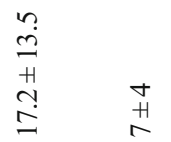

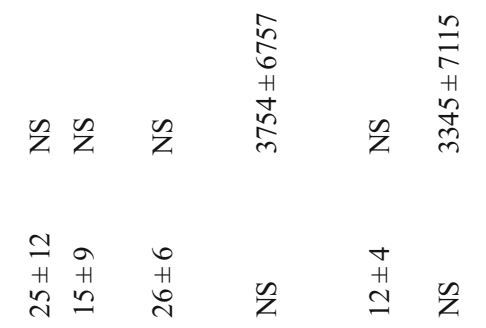

$\begin{array}{ll}\stackrel{0}{i n} \\ i \\ \stackrel{i}{i} & n\end{array}$

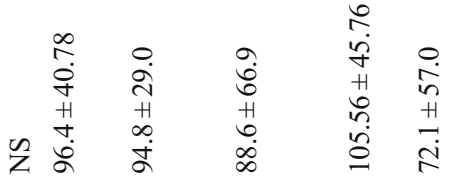

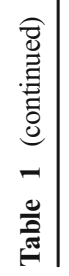

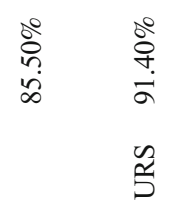

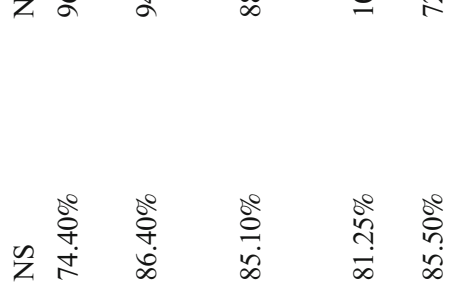




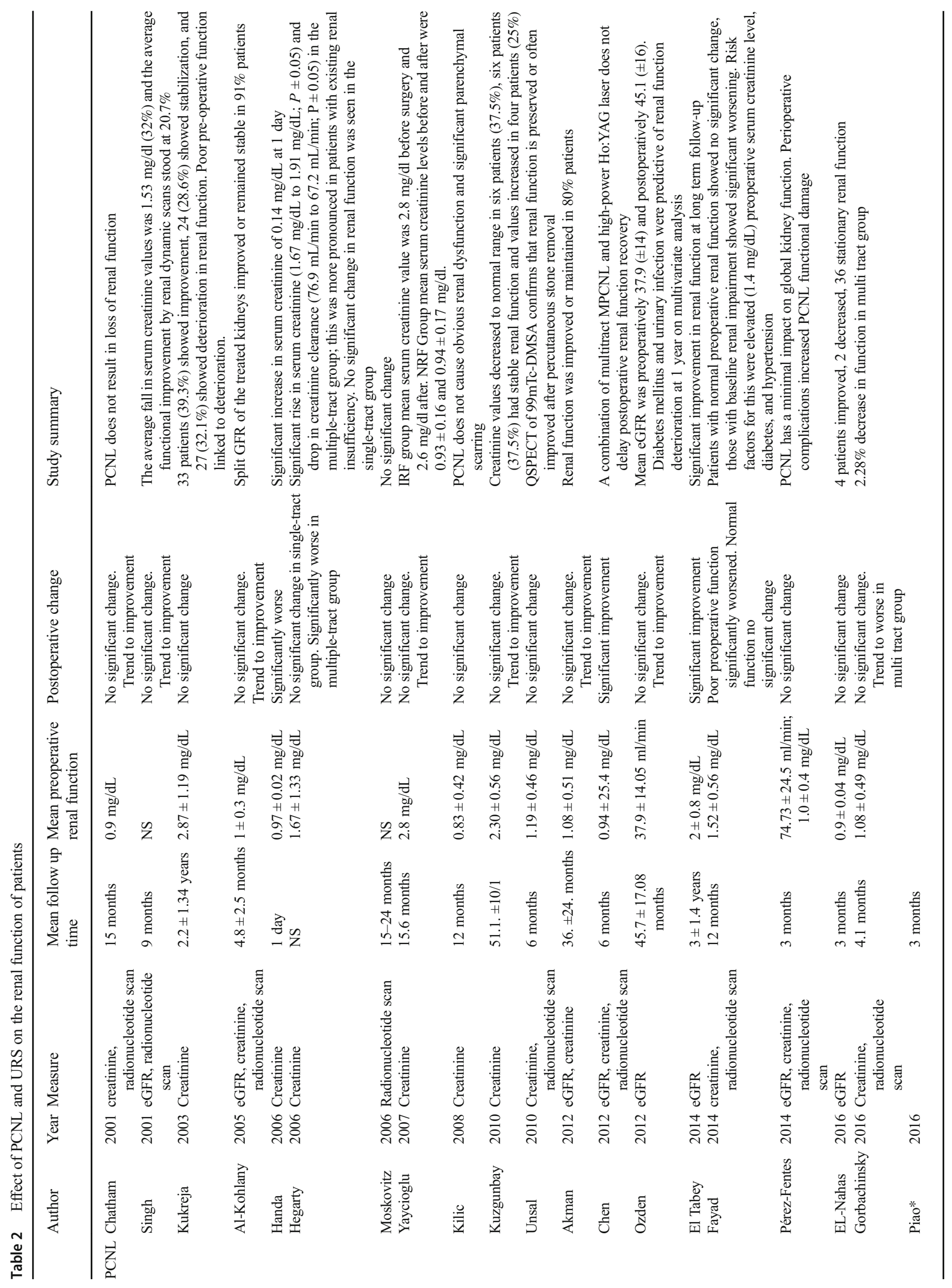




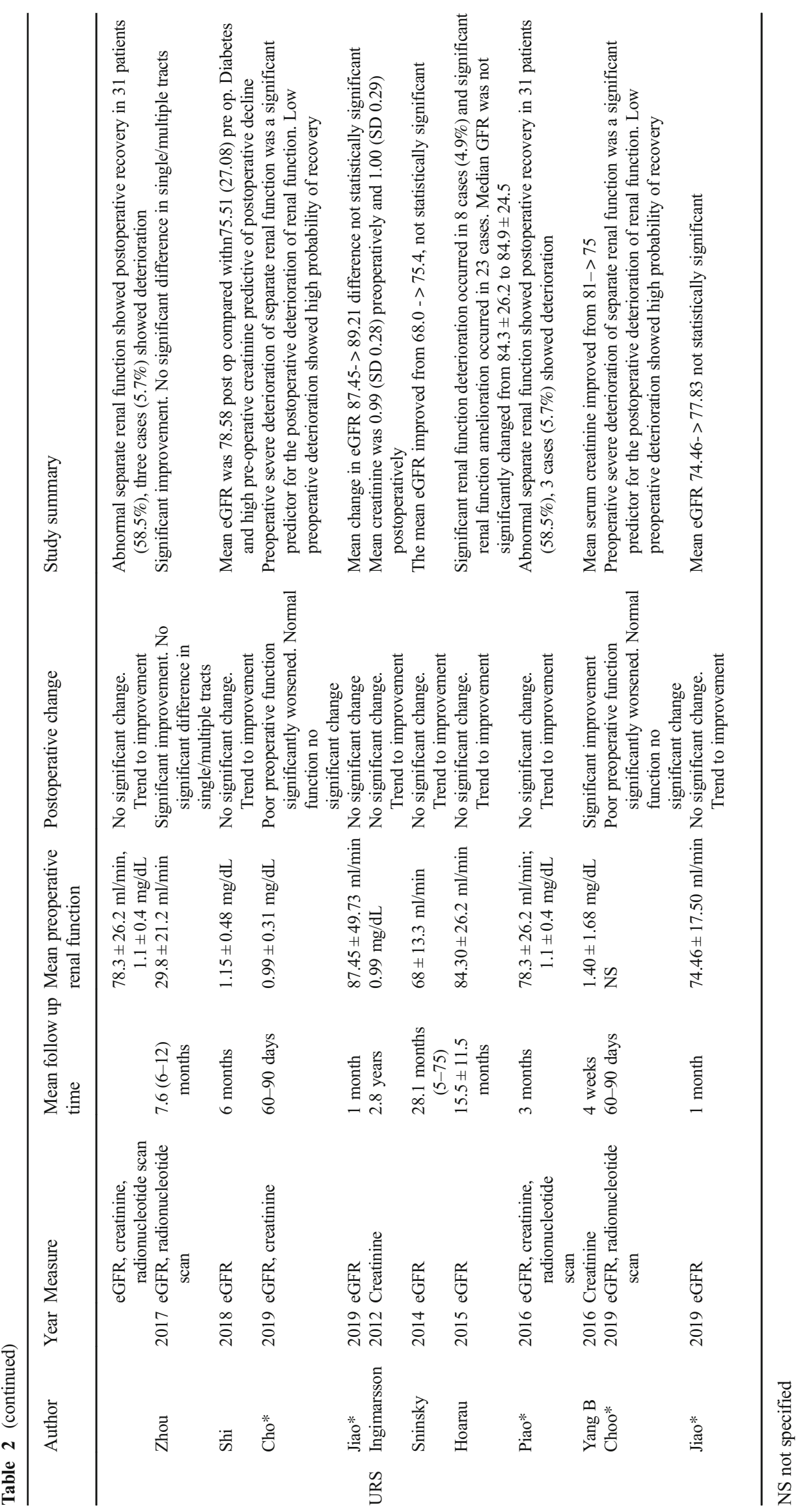




\section{Discussion}

\section{Meaning of the Study}

Here we present the only systematic review on the effect of PCNL and URS on renal function. Our study suggests that overall renal function is not detrimentally affected by endourological intervention, but there are potentially some important predictive factors including preoperative renal function, diabetes, and hypertension, hence patients should be appropriately counseled and followed up.

For patients undergoing PCNL, the results were varied. Handa et al. showed a significantly worse postoperative renal function but their follow up time frame was only 1 day, and this may not have been replicated at subsequent follow up [15]. Gorbachinsky et al., Hegarty et al., and El-Tabey et al. showed that multiple tracts were predictive of significant deterioration in renal function [19, 20,32]. This is perhaps a reflection of the theoretical risk of parenchymal damage causing a decline in renal function, but this wasn't replicated across all studies using multiple tracts. Several studies showed that a poor preoperative renal function was predictive of the postoperative function $[23,31$, 41]. Additionally, Fayad et al. showed that diabetes and hypertension were independent risk factors for poor outcome [31], ElTabey et al. showed that postoperative bleeding was a factor [19], and Ozden et al. showed that diabetes and urinary tract infection were independent factors [23]. This suggests that declining renal function maybe attributable to patient comorbidities and other underlying disease as opposed to the effect of the endourological procedure alone. Especially as three studies showed significant improvement in function, and the majority of others showed a trend toward improvement [19, 30, 35].

With patients undergoing ureteroscopy only, Yang et al. showed a significant improvement in postoperative renal function [36]. Cho et al. demonstrated that poor preoperative renal function predicated deterioration, but the renal function was protected for those with good pre-operative renal function [41]. All the other studies showed a trend towards improvement of renal function. Interestingly Sninksy et al. concluded that there was no association between poor preoperative function or multiple procedures on the post-procedural function [37].

\section{Strengths, Limitations, and Areas for Future Research}

This study gives and overview of the effect of endourological techniques effect on renal function. Due to the heterogeneity of the studies and methods for monitoring renal function metaanalysis was not possible; this also made it difficult to compare the studies directly. The patient population inherently contains a number of confounders in terms of comorbidities. In addition, many of papers were retrospective case series and prone to bias. It is prudent that future studies look at the procedural cost differences and quality of life in these patients [43-45]. Similarly, the laser settings and the heat generated by them need to be addressed especially in the context of patients with poor-preoperative renal function [46].

The review highlights that although the renal function is unaffected in most endourological interventions, yet there is a lack of prospective real-life data addressing this issue. Similarly, perhaps there is a need for a randomized control trial addressing both PCNL and URS, with an emphasis on pre- and postoperative renal function, taking into consideration the comorbidities such as diabetes, hypertension, obesity, and chronic kidney disease [47]. This is especially important as previous studies have shown a direct link of these factors on the renal function [48]. Identification of high-risk patients and periodic monitoring of renal function would help in early intervention and is likely to protect further deterioration [49]. PCNL does not seem to result in loss of renal function [29]. However, increasing multiplicity of tracts seems to negatively impact the renal function [50]. Minimally invasive PCNL however does not seem to effect renal function even when there are multiple tracts [35]. In patients with pre-existing CKD or diabetes/hypertension and non-obstructed pelvicalyceal system multi-tract PCNL may result in a kidney function deterioration and thus endoscopic combined intrarenal surgery (ECIRS) should be contemplated [51].

\section{Conclusion}

This review suggests that endourological interventions do not adversely affect renal function and tend to improve it in patients who do not have a poor renal function prior to the procedure. Several factors including poor preoperative renal function, diabetes, hypertension, and multiple percutaneous tracts appear to predispose patients to declining renal function after procedure, and these patients should be counseled for and followed up appropriately.

\section{Compliance with Ethical Standards}

Conflict of Interest The authors declare that they have no conflict of interest.

Human and Animal Rights and Informed Consent This article does not contain any studies with human or animal subjects performed by any of the authors.

Open Access This article is licensed under a Creative Commons Attribution 4.0 International License, which permits use, sharing, adaptation, distribution and reproduction in any medium or format, as long as you give appropriate credit to the original author(s) and the source, provide a link to the Creative Commons licence, and indicate if changes were made. The images or other third party material in this article are included in the article's Creative Commons licence, unless indicated otherwise in a credit line to the material. If material is not included in the article's Creative Commons licence and your intended use is not permitted by statutory regulation or exceeds the permitted use, you will need to obtain permission directly from the copyright holder. To view a copy of this licence, visit http://creativecommons.org/licenses/by/4.0/. 


\section{References}

1. Raheem OA, Khandwala YS, Sur RL, Ghani KR, Denstedt JD. Burden of urolithiasis: trends in prevalence, treatments, and costs. Eur Urol Focus. 2017;3(1):18-26.

2. Rukin N, Siddiqui Z, Chedgy E, Somani BK. Trends in upper tract stone disease in England: evidence from the hospital episodes statistics (HES) database. Urol Int. 2017;98(4):391-6.

3. Pietropaolo A, Proietti S, Geraghty R, et al. Trends of 'urolithiasis: interventions, simulation and laser technology' over the last 16 years (2000-2015) as published in the literature (PubMed): a systematic review. World J Urol. 2017;35(11):1651-8.

4. Ghosh A, Somani BK. Safety and feasibility of day case ureteroscopy and laser lithotripsy (URSL) in patients with a solitary kidney. Cent European J Urol. 2016;69(1):91-5.

5. Jones P, Elmussareh M, Aboumarzouk OM, Mucksavage P, Somani BK. Role of minimally invasive (micro and ultra-mini) PCNL for adult urinary stone disease in the modern era: evidence from a systematic review. Curr Urol Rep. 2018;19(4):27.

6. Türk C, Petř́k A, Sarica K, Seitz C, Skolarikos A, Straub M, et al. EAU guidelines on interventional treatment for urolithiasis. Eur Urol. 2016;69(3):475-82.

7. Geraghty R, Proietti S, Traxer O, Archer M, Somani BK. Worldwide impact of warmer seasons on the incidence of renal colic and kidney stone disease (KSD): evidence from a systematic review of literature. J Endourol. 2017;31(8):729-35.

8. Rob S, Bryant T, Wilson I, Somani BK. Ultra low dose, low dose and standard dose CTKUB: is there a difference?' results from a systematic review of literature. Clin Radiol. 2017;72(1):11-5.

9. Emiliani E, Talso M, Baghdadi M, et al. Renal parenchyma injury after percutaneous nephrolithotomy tract dilatations in pig and cadaveric kidney models. Cent European J Urol. 2017;70(1):69-75.

10. Winship B, Wollin D, Carlos E, Peters C, Li J, Terry R, et al. The rise and fall of high temperatures during ureteroscopic holmium laser lithotripsy. J Endourol. 2019;33(10):794-9.

11. Tokas T, Herrmann TRW, Skolarikos A, et al. Pressure matters: intrarenal pressures during normal and pathological conditions, and impact of increased values to renal physiology. World J Urol. 2019;37(1):125-31.

12. Liberati A, Altman DG, Tetzlaff J, Mulrow C, Gøtzsche PC, Ioannidis JP, et al. The PRISMA statement for reporting systematic reviews and meta-analyses of studies that evaluate health care interventions: explanation and elaboration. Ann Intern Med. 2009;151(4):W65-94.

13. Oxford centre for evidence-based medicine - Levels of evidence. https://www.cebm.net/2009/06/oxford-centre-evidence-basedmedicine-levels-evidence-march-2009/ (accessed Nov 2019).

14. Masse J. Strengthening the reporting of observational studies in epidemiology-molecular epidemiology (STROBE-ME): an extension of the STROBE statement. J Clin Epidemiol. 2013;66(1):113.

15. Handa RK, Matlaga BR, Connors BA, Ying J, Paterson RF, Kuo $\mathrm{RL}$, et al. Acute effects of percutaneous tract dilation on renal function and structure. J Endourol. 2006;20(12):1030-40.

16. Kuzgunbay B, Gul U, Turunc T, Egilmez T, Ozkardes H, Yaycioglu $\mathrm{O}$. Long-term renal function and stone recurrence after percutaneous nephrolithotomy in patients with renal insufficiency. $\mathrm{J}$ Endourol. 2010;24(2):305-8.

17. Akman T, Binbay M, Aslan R, Yuruk E, Ozgor F, Tekinarslan E, et al. Long-term outcomes of percutaneous nephrolithotomy in 177 patients with chronic kidney disease: a single center experience. J Urol. 2012;187(1):173-7.

18. El-Nahas AR, Elshal AM, El-Tabey NA, et al. Percutaneous nephrolithotomy for staghorn stones: a randomised trial comparing high-power holmium laser versus ultrasonic lithotripsy. [Article]. BJU Int. 2016;118(2):307-12.
19. El-Tabey NA, El-Nahas AR, Eraky I, et al. Long-term functional outcome of percutaneous nephrolithotomy in solitary kidney. Urology. 2014;83(5):1011-5.

20. Hegarty NJ, Desai MM. Percutaneous nephrolithotomy requiring multiple tracts: comparison of morbidity with single-tract procedures. J Endourol. 2006;20(10):753-60.

21. Kilic S, Altinok T, Altunoluk B, et al. Long-term effects of percutaneous nephrolithotomy on renal morphology and arterial vascular resistance as evaluated by color Doppler ultrasonography: preliminary report. Urol Res. 2006;34(3):178-83.

22. Kukreja R, Desai M, Patel SH, Desai MR. Nephrolithiasis associated with renal insufficiency: factors predicting outcome. J Endourol. 2003;17(10):875-9.

23. Ozden E, Mercimek MN, Bostanci Y, et al. Long-term outcomes of percutaneous nephrolithotomy in patients with chronic kidney disease: a single-center experience. Urology. 2012;79(5):990-4.

24. Shi X, Peng Y, Li L, Li X, Wang Q, Zhang W, et al. Renal function changes after percutaneous nephrolithotomy in patients with renal calculi with a solitary kidney compared to bilateral kidneys. BJU Int. 2018;122(4):633-8.

25. Yaycioglu O, Egilmez T, Gul U, Turunc T, Ozkardes H. Percutaneous nephrolithotomy in patients with normal versus impaired renal function. Urol Res. 2007;35(2):101-5.

26. Moskovitz B, Halachmi S, Sopov V, Burbara J, Horev N, Groshar $\mathrm{D}$, et al. Effect of percutaneous nephrolithotripsy on renal function: assessment with quantitative SPECT of (99m)Tc-DMSA renal scintigraphy. J Endourol. 2006;20(2):102-6.

27. Unsal A, Koca G, Resorlu B, et al. Effect of percutaneous nephrolithotomy and tract dilatation methods on renal function: assessment by quantitative single-photon emission computed tomography of technetium-99m-dimercaptosuccinic acid uptake by the kidneys. J Endourol. 2010;24(9):1497-502.

28. Al-Kohlany KM, Shokeir AA, Mosbah A, et al. Treatment of complete staghorn stones: a prospective randomized comparison of open surgery versus percutaneous nephrolithotomy. J Urol. 2005;173(2):469-73.

29. Chatham JR, Dykes TE, Kennon WG, et al. Effect of percutaneous nephrolithotomy on differential renal function as measured by mercaptoacetyl triglycine nuclear renography. Urology. 2002;59(4):522-5 discussion 5-6.

30. Chen S, Zhu L, Yang S, Wu W, Liao L, Tan J. High- vs low-power holmium laser lithotripsy: a prospective, randomized study in patients undergoing multitract minipercutaneous nephrolithotomy. Urology. 2012;79(2):293-7.

31. Fayad AS, Elsheikh MG, Mosharafa A, el-Sergany R, AbdelRassoul MA, Elshenofy A, et al. Effect of multiple access tracts during percutaneous nephrolithotomy on renal function: evaluation of risk factors for renal function deterioration. J Endourol. 2014;28(7):775-9.

32. Gorbachinsky I, Wood K, Colaco M, Hemal S, Mettu J, Mirzazadeh $\mathrm{M}$, et al. Evaluation of renal function after percutaneous nephrolithotomy-does the number of percutaneous access tracts matter? J Urol. 2016;196(1):131-6.

33. Perez-Fentes D, Cortes J, Gude F, et al. Does percutaneous nephrolithotomy and its outcomes have an impact on renal function? Quantitative analysis using SPECT-CT DMSA. Urolithiasis. 2014;42(5):461-7.

34. Singh I, Gupta NP, Hemal AK, Aron M, Dogra PN, Seth A. Efficacy and outcome of surgical intervention in patients with nephrolithiasis and chronic renal failure. Int Urol Nephrol. 2001;33(2):293-8.

35. Zhou Y, Gurioli A, Luo J, Li Z, Zhu J, Li J, et al. Comparison of effect of minimally invasive percutaneous nephrolithotomy on split renal function: single tract vs multiple tracts. J Endourol. 2017;31(4):361-5. 
36. Yang B, Ning H, Liu Z, Zhang Y, Yu C, Zhang X, et al. Safety and efficacy of flexible ureteroscopy in combination with holmium laser lithotripsy for the treatment of bilateral upper urinary tract calculi. Urol Int. 2017;98(4):418-24.

37. Sninsky BC, Jhagroo RA, Astor BC, Nakada SY. Do multiple ureteroscopies alter long-term renal function? A study using estimated glomerular filtration rate. J Endourol. 2014;28(11):1295-8.

38. Ingimarsson J, Knoedler J, Amy K. Same-session bilateral ureteroscopy: safety and outcomes: MP51-08. [Miscellaneous]. J Urol. 2016;195(Supplement 4):e683-4.

39. Hoarau N, Martin F, Lebdai S, Chautard D, Culty T, Azzouzi AR, et al. Impact of retrograde flexible ureteroscopy and intracorporeal lithotripsy on kidney functional outcomes. Int Braz J Urol. 2015;41(5):920-6.

40. Jiao B, Lai S, Xu X, et al. The efficacy of flexible ureteroscopy lithotripsy and miniaturized percutaneous nephrolithotomy for the treatment of renal and proximal ureteral calculi of $<=2 \mathrm{~cm}$ : A retrospective study. [Article]. Medicine. 2019;98(11):e14535.

41. Cho S, Choo M, Lee D, et al. A prospective, observational study to investigate change of separate renal function in patients who underwent minimally invasive renal stone surgery according to the preoperative functional deterioration. J Endourol. 2016;30(Supplement 2):A86-A7.

42. Piao S, Park J, Son $\mathrm{H}$, et al. Evaluation of renal function in patients with a main renal stone larger than $1 \mathrm{~cm}$ and perioperative renal functional change in minimally invasive renal stone surgery: a prospective, observational study. World J Urol. 2016;34(5):725-32.

43. Somani BK, Robertson A, Kata SG. Decreasing cost of flexible ureterorenoscopic procedures: cost volume relationship. Urology. 2011;78(3):528-30.

44. Geraghty R, Jones P, Herrmann T, et al. Ureteroscopy seems to be clinically and financially more cost effective than shock wave lithotripsy for stone treatment: systematic review and meta-analysis. World J Urol. 2018;36(11):1783-93.

45. New F, Somani BK. A complete world literature review of quality of life in patients with kidney stone disease. Curr Urol Rep. 2016;17(12):88.

46. Kronenberg P, Somani BK. Advances in lasers for the treatment of stones. Curr Urol Rep. 2018;19(6):45.

47. Ishii $\mathrm{H}$, Couzins $\mathrm{M}$, Obumarzouk $\mathrm{O}$, et al. Outcomes of systematic review of ureteroscopy for stone disease in the obese and morbidly obese population. J Endourol. 2016;30(2):135-45.

48. Kawamoto R, Akase T, Ninomiya D, Kumagi T, Kikuchi A. Metabolic syndrome is a predictor of decreased renal function among community-dwelling middle-aged and elderly Japanese. Int Urol Nephrol. 2019;51:2285-94. https://doi.org/10.1007/ s11255-019-02320-0.

49. Moore SL, Cook P, de Conick V, et al. Outcomes and long-term follow-up of patients with cystine stones: a systematic review. Curr Urol Rep. 2019;20(6):27.

50. Yadav R, Agarwal S, Sankhwr S, et al. A prospective study evaluating impact on renal function following percutaneous nephrolithotomy using Tc99m ethylenedicysteine renal scan: does multiplicity of access tracts play a role? Investig Clin Urol. 2019;60(1):21-8.

51. Scoffone CM, Cracco CM, Cossu M, Grande S, Poggio M, Scarpa RM. Endoscopic combined intrarenal surgery in Galdakaomodified supine Valdivia position: a new standard for percutaneous nephrolithotomy? Eur Urol. 2008;54(6):1393-403.

Publisher's Note Springer Nature remains neutral with regard to jurisdictional claims in published maps and institutional affiliations. 